University of Nebraska - Lincoln

DigitalCommons@University of Nebraska - Lincoln

Pseudomonas aeruginosa Infection of the Auricular Cartilage Caused by "High Ear Piercing": A Case Report and Review of the Literature

\author{
Henry H. Rowshan \\ US Army \\ Karen Keith \\ US Army \\ Dale Baur \\ US Army \\ Peter Skidmore \\ US Army
}

Follow this and additional works at: https://digitalcommons.unl.edu/usarmyresearch

Part of the Operations Research, Systems Engineering and Industrial Engineering Commons

Rowshan, Henry H.; Keith, Karen; Baur, Dale; and Skidmore, Peter, "Pseudomonas aeruginosa Infection of the Auricular Cartilage Caused by "High Ear Piercing": A Case Report and Review of the Literature" (2008). US Army Research. 50.

https://digitalcommons.unl.edu/usarmyresearch/50

This Article is brought to you for free and open access by the U.S. Department of Defense at DigitalCommons@University of Nebraska - Lincoln. It has been accepted for inclusion in US Army Research by an authorized administrator of DigitalCommons@University of Nebraska - Lincoln. 


\title{
Pseudomonas aeruginosa Infection of the Auricular Cartilage Caused by "High Ear Piercing": A Case Report and Review of the Literature
}

\author{
MAJ Henry H. Rowshan, DDS, US Army Dental Corps, * \\ LTC Karen Keith, DDS, MD, US Army Dental Corps, $†$ \\ COL Dale Baur, DDS, MD, US Army Dental Corps, $\neq$ and \\ LTC Peter Skidmore, MD, FACP, US Army Medical Corps $\mathfrak{I}$
}

Piercing of various parts of the body has gained tremendous popularity among adolescent and adult populations in recent years. There are no exact statistical reports on the number of body piercings being performed in the United States. One study among 481 college students in New York revealed that $42 \%$ of men and $60 \%$ of women had body piercing. ${ }^{1}$ In the past, the majority of complications of ear piercing were associated with the lobule. Torn ear lobes, localized infection, hypertrophic scars, allergic contact dermatitis, and keloid formations were among the most common, with no significant morbidity. ${ }^{2}$ However, "high ear piercing," defined as piercing through the ear cartilage, is now very popular. Because of the lack of vascularity, piercing of the ear cartilage has been associated with a higher incidence of infections than the lobule. Staphylococcus and Pseudomonas aeruginosa are the most common causative organ-

\footnotetext{
Received from Eisenhower Army Medical Center, Fort Gordon, GA. "Chief Resident, Oral and Maxillofacial Surgery.

†Assistant Program Director, Oral and Maxillofacial Surgery.

‡Formerly, Program Director, Chief of Department, Oral and Maxillofacial Surgery; and Currently, Associate Professor and Chair, Department of Oral and Maxillofacial Surgery, Case Western Reserve University/University Hospitals, Cleveland, $\mathrm{OH}$.

§Program Director, Internal Medicine Residency, Department of Internal Medicine, Infectious Disease Division.

Address correspondence and reprint requests to Col Baur: Eisenhower Army Medical Center, Department of Oral and Maxillofacial Surgery, 300 East Hospital Road, Fort Gordon, GA 30905; e-mail: hrowshan@excite.com

This is a US government work. There are no restrictions on its use. Published by Elsevier, Inc on behalf of the American Association of Oral and Maxillofacial Surgeons.

0278-2391/08/6603-0020\$34.00/0

doi: 10.1016/i.joms.2006.10.045
}

isms. ${ }^{3}$ Most commonly, such infections occur in newly pierced ears and in the warm-weather months of the year. These infections can lead to significant perichondritis and necrosis of the auricular cartilage, often resulting in permanent disfigurement and reconstructive challenges. The oral and maxillofacial surgeon may be presented with such cases and must be familiar with the prompt treatment protocol of the infection.

\section{Report of a Case}

A 20-year-old Asian American woman presented to the emergency department 3 weeks after receiving a piercing of her right helical rim at a local shopping mall. Approximately 1 week before admission she started to experience aching and edema in the right ear at the site of the piercing. The patient removed the earring and had no resolution of her symptoms. Over the next few days, the ear became exquisitely tender, erythematous, and ecchymotic, with some purulent exudate from the piercing site. The edema and ecchymosis extended into the conchal bowl.

Upon consultation with the oral and maxillofacial service, the patient complained of $6 / 10$ pain in the right ear with referred pain to the neck area. She denied fevers, chills, nausea, vomiting, or significant headache. She reported no allergy to nickel or other metals. Head and neck examination revealed a $1 \mathrm{~cm} \times 1 \mathrm{~cm}$, tender, nonfluctuant swelling along the helix and posterior auricular area of the right ear (Figs 1,2). No significant purulence was observed on palpation of the mass. The patient had no lymphadenopathy. The right tympanic membrane appeared normal, and the external auditory canal was clear. Hearing was unimpaired. No cranial nerve dysfunction was noted. Her neck had full range of motion and she had negative Kernig and Brudzinski signs. Her vital signs were as follows: blood pressure, 106/61 mmHg; heart rate, $83 \mathrm{PBM}$; temperature, $97.6^{\circ} \mathrm{F}$. Her laboratory results revealed no leukocytosis (white blood cell count, $8.8 \times 10^{3}$ ) with normal hemoglobin $(14)$ and hematocrit $(41 \%)$ and normal platelet count $\left(332 \times 10^{3}\right)$.

The patient underwent incision and drainage in the clinic under local anesthesia with minimal discharge from the surgical site. Intravenous cefazolin, $1 \mathrm{~g}$, was administered 
empirically. Aerobic and anaerobic cultures were submitted. An intravenous catheter tubing was placed within the wound as a means for continuous drainage of the surgical site (Figs 3, 4). After 24 hours of inpatient observation, the patient was sent home with keflex $500 \mathrm{mg}$ orally 4 times daily for 10 days.

On the third postoperative day, the patient returned for drain removal. No significant improvement in the edema or erythema was noted. Purulent exudate was evident within the drain. The wound was reopened, debrided, and irrigated. Examination of the wound culture results showed light growth of Pseudomonas aeruginosa. The patient was subsequently placed on ciprofloxacin $750 \mathrm{mg}$ twice daily for 14 days and keflex was discontinued.

Six days after the initial drainage, much of the auricular edema had resolved. The erythema completely disappeared and the patient had no pain. This patient's ear healed well with no deformity of the helical rim or conchal bowl (Fig 5).

\section{Discussion}

The ear is currently the most common site of body piercing, with multiple piercings, especially transcartilaginous, becoming extremely popular. Complications associated with piercings are increasing as well. Most are relatively minor, with little morbidity, because the ear lobule is still the most commonly pierced site. Piercing of auricular cartilage, however, can result in significant morbidity because of its avascular nature. If necrosis results in significant tissue loss, the patient will have a defect requiring potentially very challenging reconstruction. Those inter-

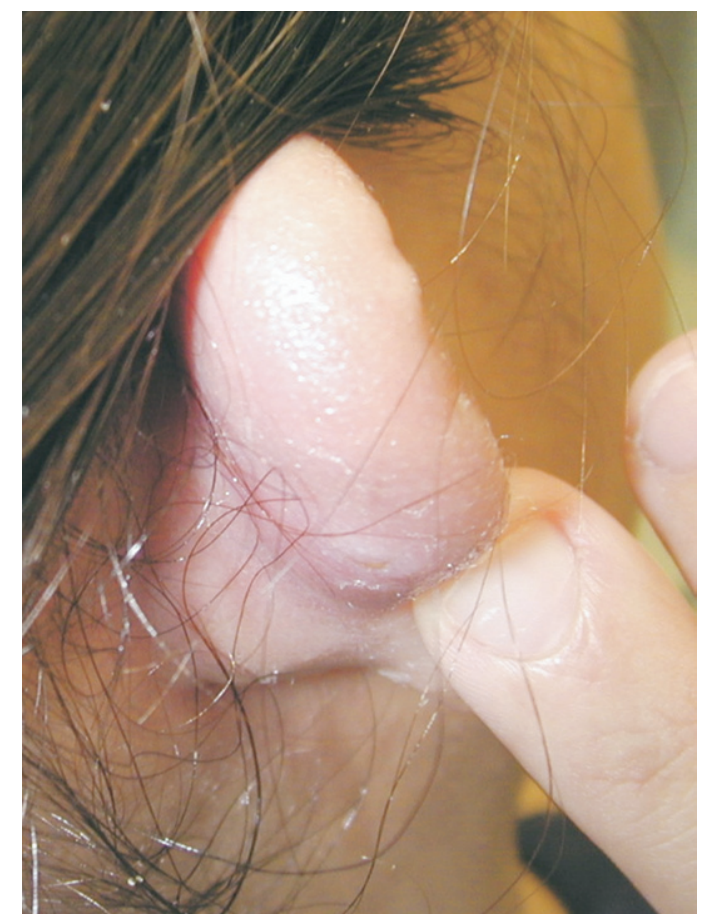

FIGURE 1. Initial presentation: note diffuse auricular edema.

Rowshan et al. Pseudomonas aeruginosa Infection. J Oral Maxillofac Surg 2008.

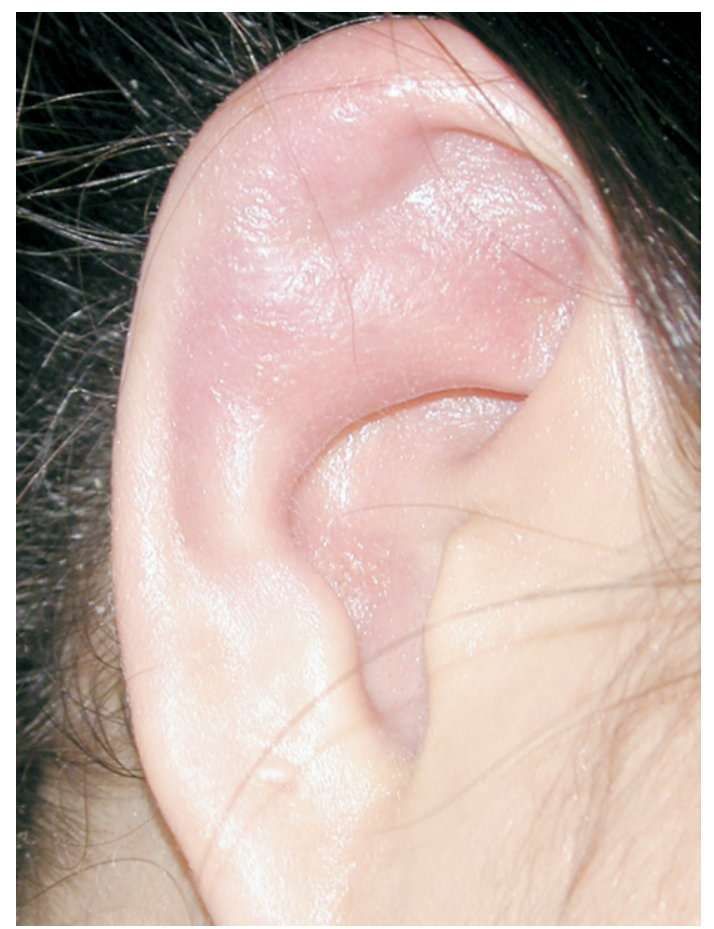

FIGURE 2. Initial presentation: note diffuse auricular edema

Rowshan et al. Pseudomonas aeruginosa Infection. J Oral Maxil lofac Surg 2008

ested in such piercings should be aware of the risks before consenting to such procedures.

In 2000, Oregon had an outbreak of pseudomonas auricular cartilage infections that were all linked to a

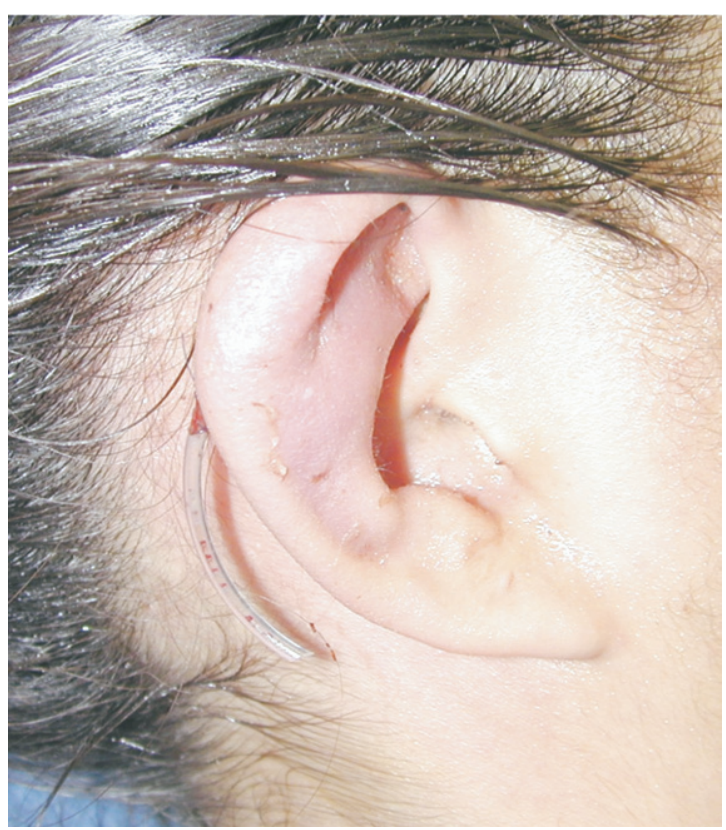

FIGURE 3. Intravenous tubing used for wound drainage.

Rowshan et al. Pseudomonas aeruginosa Infection. J Oral Maxillofac Surg 2008. 


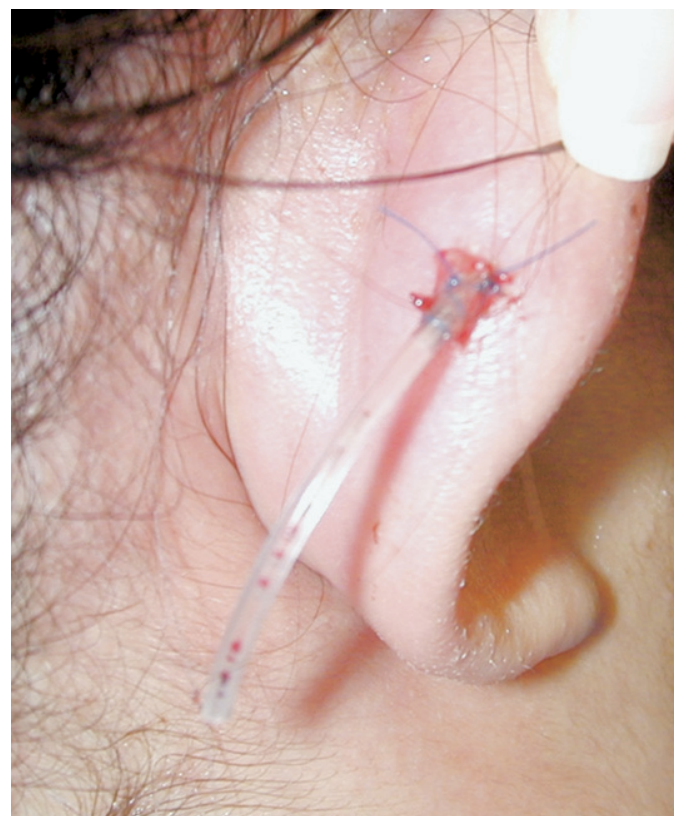

FIGURE 4. Intravenous tubing used for wound drainage.

Rowshan et al. Pseudomonas aeruginosa Infection. J Oral Maxillofac Surg 2008.

jewelry kiosk at a local shopping mall. The etiology for this particular outbreak was the disinfectant bottle that was being refilled repeatedly with contaminated water and used to clean the piercing gun. ${ }^{4}$ Piercing gun use has been associated with a higher incidence of chondritis. It was first developed to mark the ears of cattle. Its use causes significant shearing forces, which tear the perichondrium from the cartilage and can lead to necrosis of the underlying cartilage. It is not routinely autoclaved by the vendors, but is wiped with an antiseptic solution between uses. In many states, including Oregon, piercing guns are not legal for piercing cartilage. Because of sterility issues, the Association of Professional Piercers does not endorse the use of piercing guns for cartilage. ${ }^{5}$ Instead, they recommend sterile needles to minimize the chance of transmitting organisms to an avascular anatomic region. Additional factors increasing the risk of infection include the improper training of employees in piercing techniques, the use of sterile versus nonsterile gloves, the handling of the sterile earring with contaminated equipment, the inadequate cleansing and preparation of the piercing site, and the failure to provide proper post piercing hygiene instructions. ${ }^{4}$

Postpiercing infections usually occur 3 to 4 weeks after the event. The ear can resemble a cellulitis with erythema and tenderness of the pinna. The edema can spread throughout the auricle, usually sparing the lobule. Once the perichondrium is involved, the patient will have exquisite tenderness, as potential spaces are expanded and stretched. This can progress quickly to perichondritis, abscess, and necrosis of involved cartilage. Clients should be informed as to what is considered a normal postpiercing course. If there is any concern about prolonged redness, soreness, or increasing swelling, the client should seek medical attention early. Waiting for several weeks for medical intervention can be detrimental to the ear. ${ }^{6}$

The most common antiseptic solutions used by cosmetic jewelry shops are benzalkonium chloride, isopropyl alcohol pads, and iodine-povidone solution. Benzalkonium chloride is active against gram-positive and gram-negative bacteria, but is ineffective against strains of pseudomonas as well as other spore forming bacteria. Benzalkonium chloride has also been shown to become inactivated by gauze and cotton pads. Isopropyl alcohol is effective against pseudomonas, but ineffective against spore-forming bacteria. Iodine solution is routinely used in the surgical setting and is effective against bacteria, including pseudomonas. However, it may cause skin irritation and allergic reactions in patients with known iodine hypersensitivity. Additionally, it may discolor local tissue and clothing, which may not be acceptable to the customers visiting piercing establishments. ${ }^{7}$

Pseudomonas aeurginosa is now known to be the causative organism in approximately $95 \%$ of patients with transcartilaginous ear piercing infections. Pseudomonas is a gram-negative, aerobic rod belonging to the bacterial family Pseudomonadaceae. It is an opportunistic pathogen that exploits some break in

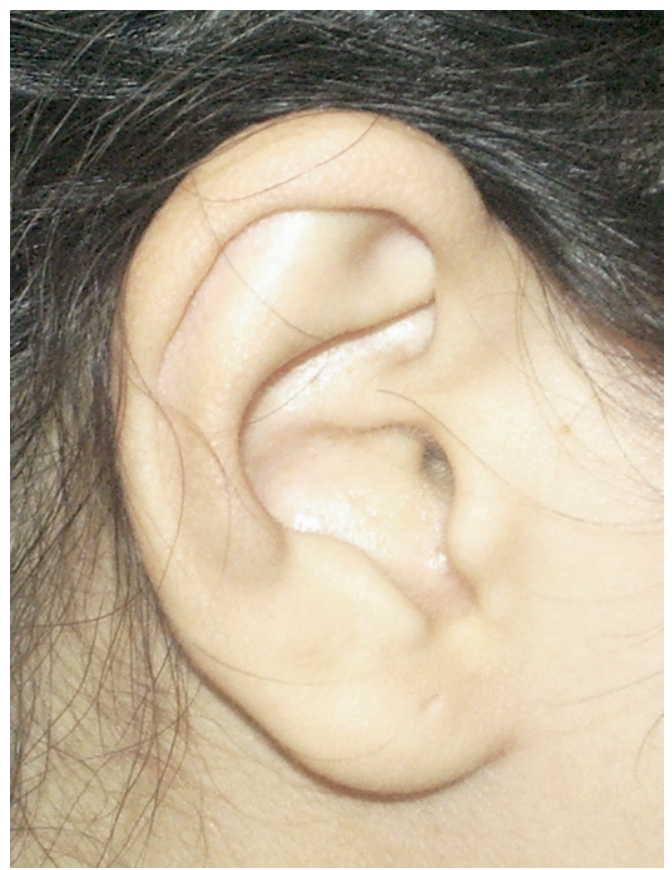

FIGURE 5. Postoperative resolution of infection after 6 days

Rowshan et al. Pseudomonas aeruginosa Infection. J Oral Maxillofac Surg 2008. 
the host defenses to initiate an infection. The bacterium is normally found in soil and water and on surfaces in contact with a moist environment. This explains the higher incidence of infection in the warm and moist environment periods of the year. ${ }^{6}$ Pseudomonas aeruginosa produces 3 colony appearances: a rough, a smooth, and a mucoid type. The smooth and mucoid types are associated with clinical colonization and virulence. Pseudomonas is a pathogen with resistance to many antibiotics, including first and second generation cephalosporins. It has the ability to maintain antibiotic resistance and transfer such resistance genes though processes of transduction and conjugation. ${ }^{8}$

Since their introduction in the United States over 2 decades ago, fluoroquinolones have become a mainstay in the treatment of serious bacterial infections in adults. They have a broad spectrum of antibacterial activity and are bacteriocidal agents that interfere with the enzyme DNA-gyrase to inhibit bacterial DNA synthesis. Ciprofloxacin and levofloxacin are effective against most gram-negative organisms, including Pseudomonas aeruginosa. Gram-positive coverage includes most species of staphylococcus and streptococcus, including many beta-lactam resistant strains. This makes fluoroquinolones an ideal antibiotic for the treatment of auricular ear cartilage infection. Flouroquinolones are generally not effective against anaerobes. ${ }^{9}$ In our patient, a flouroquinolone should have been chosen as the initial empiric antibiotic of choice.

It is worthwhile to note that the pediatric literature advises against using fluoroquinolones in children under 18 years of age. Animal studies have shown serious cartilage erosion and joint malformation and as a result such agents were labeled contraindicated in children. The use of ceftazidime (Fortaz; GlaxoSmithKline, New York, NY), a third generation cephalosporin with high activity against pseudomonas, is an alternative. $^{10}$

If a piercing site becomes infected, close monitoring and aggressive intervention are warranted to pre- vent serious sequelae. Surgical debridement and copious irrigation and drainage need to be frequently performed. Cultures should be obtained to guide appropriate antibiotic therapy.

This case illustrates a more serious infection course that can result after piercing of the auricular cartilage. It serves as a reminder to ensure asepsis and post piercing hygiene as well as close follow-up during the healing phase to prevent a potentially very morbid outcome. Surgeons should be aware that Pseudomonas and Staphylococcus are the most frequent organisms involved in these aggressive infections. Appropriate antibiotics, combined with prompt surgical debridement and drainage, are essential to avoid permanent disfigurement. In light of the possible adverse sequelae associated with cartilage or high ear piercing, clients should be thoroughly counseled regarding the risks and should take steps to be adequately educated.

\section{References}

1. Stirn A: Body piercing: Medical consequences and psychological motivations. Lancet 361:1205, 2003

2. Hendricks WM: Complications of ear piercing: Treatment and prevention. Cutis 48:386, 1991

3. Meltzer DI: Complications of body piercing. Am Fam Physician 72:2029, 2005

4. Keene W, Markum A, Samadpour M: Outbreak of Pseudomonas aeruginosa infection caused by commercial piercing of upper ear cartilage. JAMA 291:281, 2004

5. The Association of Professional Piercers website: Available at: http://www.safepiercing.org/index.html. Accessed November 8, 2006

6. Hamif J, Frosh A, Marnane C, et al: High ear piercing and the rising incidence of perichondritis of the pinna. BMJ 322:906, 2001

7. More D, Siedel J, Bryan P: Ear-piercing technique as a cause of auricular chondritis. Pediatr Emerg Care 15:189, 1999

8. Kennet Todar: http.//textbookofbacteriology.net/pseudomonas. html. Accessed November 29, 2006

9. Noel SB, Scallan P, Meadons MC, et al: Treatment of pseudomonas auricular perichondritis with oral ciprofloxacin. J Dermatol Surg Oncol 15:633, 1989

10. Brooks FG, Butel JS, Morse SA: Pseudomonads, Acinetobacters, \& uncommon gram-negative bacteria, in Medical Microbiology (ed 22). Baltimore, MD, Lange Medical Books/McGraw-Hill, 2001, pp 229-231 